Check for updates

\title{
O ABALO EDUCACIONAL NA PRIMEIRA ONDA DO COVID-19
}

\author{
THE EDUCATIONAL SHOCK IN THE FIRST WAVE OF COVID-19
}

Renata Barbosa Del Ducca Pós-graduada em Gestão Escolar Faculdade Dom Alberto. Itajubá, MG - Brasil. renatadelducca@gmail.com

Éderson José de Vasconcelos Mestre em História Ibérica Universidade Federal de Alfenas - Unifal -MG. Itajubá, MG - Brasil. ederson_vasconcelos@hotmail.com

Resumo: O presente artigo tem por objetivo investigar aspectos da educação perante a nova forma de trabalho remoto das escolas de ensino regular durante o primeiro momento de adaptação à pandemia de Coronavírus. Desta maneira, optamos em fazer a estrutura de nosso estudo apresentando o que foi a pandemia, como ela se alastrou pelo mundo, quais foram as medidas tomadas no Brasil, e posteriormente, realizar o estudo de caso referente ao nosso recorte espacial. O trabalho se deu através de levantamento de dados em forma de entrevista a funcionários que atuam na comunidade escolar na região de Itajubá, Sul de Minas Gerais, no período compreendido entre março e novembro de 2020. Como a pandemia ainda faz com que a educação trabalhe de forma remota sem previsão de retomada das atividades presenciais, alcançamos alguns resultados prévios do impacto inicial no setor educacional.

Palavras-chave: pandemia; ensino remoto; coronavirus; educação.

Abstract: This research aims to investigate aspects of education in the face of the new form of remote work at regular schools during the first moment of adaptation to the Coronavirus pandemic. Therefore, we opt to structure our paper presenting what the pandemic was, how it spread around the world, and the actions created in Brazil, next that perform a data collection about the place outlined. The research is a result of data collection from school workers interviews in the South of Minas Gerais, in the period between March and November 2020. As the pandemic still forces the education happens online, without estimate of live attend return, we achieve some initial results of the impact in the educational area.

Keywords: pandemic; remote teaching; coronavírus; education.

\section{Para citar - ABNT NBR 6023:2018}

DUCCA, Renata Barbosa Del; VASCONCELOS, Éderson José. O abalo educacional na primeira onda do COVID19. Cadernos de Pós-graduação, São Paulo, v. 20, n. 1, p. 4 -16, jul./dez. 2021. Disponível em:

https://doi.org/10.5585/cpg.v20n1.18467. 


\section{Introdução}

O tema que iremos abordar em nosso trabalho refere-se aos impactos causados pela pandemia de Coronavírus nos setores de educação durante os meses de março a novembro do ano de 2020 e como a comunidade escolar se adequou a esta nova realidade de ensino remoto em um primeiro momento de tomadas de decisões.

Optamos em desenvolver esta pesquisa, uma vez que se trata de um fato ainda recente que causou várias modificações dentro do cotidiano escolar durante o ano de 2020. Desta forma, buscamos compreender como gestores escolares, professores, funcionários das escolas, auxiliares de educação se comportaram durante tal pandemia de Covid-19.

Neste sentido, o nosso tema de pesquisa retrata como a comunidade escolar se adequou a esta nova realidade no ano letivo de 2020 , e quais foram os possíveis problemas e soluções para a retomada das aulas.

Considerando que a sala de aula teve um curto tempo para a adaptação de seu novo formato e os professores, os quais muitos ainda apresentam dificuldades com novas tecnologias, levantamos a hipótese que o ensino sofreu grandes perdas educacionais pelo tempo de tomada de decisões e pela adaptação da nova metodologia de aprendizagem. Como ainda temos poucas respostas sobre a adaptação da comunidade escolar a este contexto histórico, uma vez que ainda este se encontra em desenvolvimento, sentimos a necessidade de questionar esta comunidade como foram suas possíveis adaptações no ano de 2020.

Já no âmbito objetivo de nossa pesquisa, buscamos compreender os impactos do ensino remoto dentro da comunidade escolar, uma vez que esta situação em que vivemos nesse período, não havia ocorrido anteriormente neste século, e também foi a primeira vez na história da humanidade que a tecnologia foi utilizada em larga escala para o desenvolvimento do ensino, e como isso afetou o trabalho da comunidade escolar, que timidamente usava recursos tecnológicos até então.

A justificativa para o presente trabalho é o caráter de inovação dentro das pesquisas em educação. Uma vez que ainda são recentes os impactos do uso da tecnologia no cotidiano escolar, assim como também a adaptação da comunidade escolar ao ensino remoto, e como estas inovações vem sendo compreendidas por esta comunidade.

A metodologia utilizada em nossa pesquisa foi o trabalho de campo, no qual desenvolvemos um questionário via plataforma online Google Forms ${ }^{1}$, uma vez que a população brasileira se

\footnotetext{
${ }^{1}$ Google Forms é um aplicativo de gerenciamento de pesquisas lançado pelo Google. Os usuários podem usar o Google Forms para pesquisar e coletar informações sobre outras pessoas e também podem ser usados para questionários e formulários de registro. As informações coletadas e os resultados do questionário serão transmitidos automaticamente. Além disso, o Google Forms também possui recursos de colaboração e compartilhamento para vários usuários.
} 
encontrava em isolamento social por conta da crise mundial de Covid-19. Neste sentido fizemos um recorte geográfico e questionamos membros da comunidade escolar da região do Sul do Estado de Minas Gerais, com isso elaboramos algumas indagações para estas comunidades, assim desenvolvemos nove gráficos que abordam as principais questões sobre este tema.

\section{Contexto Histórico do Coronavírus e suas adaptações no cotidiano escolar}

No final do ano de 2019 foi noticiada uma nova doença na cidade de Wuhan, na China, o Covid-19, doença que chegou com mais de 190 mil pessoas em menos de três meses em todo o território mundial. Em 26 de fevereiro de 2020 foi confirmado o primeiro caso do novo Coronavírus no Brasil, na cidade de São Paulo. No dia 11 de março do mesmo ano, a Organização Mundial da Saúde declarou pandemia de Coronavírus, levando em consideração que em poucos dias o número de pessoas infectadas, mortes e países atingidos iriam aumentar nos dias e semanas seguintes. No Brasil, a primeira morte pelo vírus foi notificada em 17 de março e fez com que o estado do Rio de Janeiro decretasse medidas temporárias para prevenir o contágio e entre as medidas tomadas, a suspenção por 15 dias de todas as atividades com presença de público, incluindo visitas prisionais, shows, eventos e aulas nas redes públicas e particulares de ensino. Além da redução do transporte público, bem como de horário de atendimento de lojas, bares e restaurantes.

Diante da medida tomada, muitas escolas do Brasil, assim como a da rede municipal da cidade de São Paulo, decidiram dar como recesso esse primeiro momento, com intuito de antecipar o recesso que o calendário prevê em julho, de forma a não haver prejuízos no aprendizado e dias letivos previstos. Porém, passados os 15 dias, ainda não havia um cenário seguro com possibilidade de volta às aulas, e nesse momento, secretários, gestores e toda comunidade escolar iniciaram uma discussão sobre como ajustar o calendário escolar, frente à nova realidade vivida em contexto mundial.

No dia primeiro de abril de 2020, o Congresso Nacional apresentou uma medida provisória (MP 934) que estabelecia normas excepcionais sobre o ano letivo da educação básica e do ensino superior decorrentes das medidas para enfrentamento da situação de emergência de saúde pública de que trata a Lei no 13.979 , de 6 de fevereiro de 2020. A medida dispensava, em caráter excepcional, as escolas de educação básica da obrigatoriedade de cumprir o mínimo de 200 dias letivos de efetivo trabalho escolar. Determinou que a carga horária mínima de oitocentas horas deveria ser cumprida, nos termos das normas a serem editadas pelos respectivos sistemas de ensino. Dispensou as instituições de educação superior, em caráter excepcional, do cumprimento da obrigatoriedade de mínimo de dias letivos, nos termos das normas a serem editadas pelos respectivos sistemas de ensino. Estabeleceu que as referidas dispensas tivessem vigência durante o ano letivo afetado 
pelas medidas de emergências relacionadas ao novo Coronavírus. Autorizou as instituições de ensino a abreviarem a duração dos cursos de Medicina, Farmácia, Enfermagem e Fisioterapia, cumprindo as condições previstas.

É válido ressaltar também, que além de cobrarem das autoridades uma posição em relação ao novo ajuste de calendário, gestores e secretários de educação articularam medidas da distribuição da merenda escolar para que os alunos não ficassem sem o acesso à alimentação durante o período em que as escolas permanecessem fechadas. Em 7 de abril de 2020 é criada a Lei 13.987 para autorizar a distribuição de alimentos, em caráter excepcional, em razão da situação de emergência e calamidade pública, em que os gêneros alimentícios adquiridos com recursos do Programa Nacional de Alimentação Escolar fossem entregues aos pais ou responsáveis dos estudantes das escolas públicas de educação básica.

O Presidente da República, Jair Bolsonaro, contradizendo autoridades médicas de todo o país, foi a favor da abertura do comércio e das escolas. Segundo ele, a Covid-19 "é apenas uma gripezinha", entre outras declarações cujo pedido à população era que "enfrentasse a gripe como homens", já que "todos nós vamos morrer um dia”. Além de repetir inúmeras vezes em rede nacional que um remédio para o tratamento da malária já estaria funcionando contra a Covid-19, sem qualquer embasamento científico. Diante de todas essas declarações, o cenário que o Brasil passou a apresentar foi um afrouxamento das regras de isolamento e mesmo com as escolas ainda fechadas, em 30 de abril, o Brasil registrou mais casos confirmados do que a China, o país onde começou a epidemia. E segundo o estudo do Imperial College London, o Brasil é apontado como o país que tem a maior taxa de contágio da Covid-19 em todo o mundo.

E diante de todo esse caos de contradições e informações alarmantes, temos professores, gestores e toda comunidade escolar reunidos de forma virtual, em uma força tarefa na tentativa de fazer com que os prejuízos educacionais fossem minimizados. A declaração universal dos direitos humanos (10 de dezembro de 1948) prevê em seu artigo 26 que:

Todo ser humano tem direito à instrução. A instrução será gratuita, pelo menos nos graus elementares e fundamentais. A instrução elementar será obrigatória. A instrução técnicoprofissional será acessível a todos, bem como a instrução superior, está baseada no mérito. (Brasil, 1948).

Como garantir o acesso à instrução a todos os alunos em um país onde a desigualdade social e de acesso à informação são gigantes? De acordo com o artigo $3^{\circ}$ da Lei de Diretrizes e Bases da Educação Nacional: Lei no 9.394/96, o ensino será ministrado com base em diversos princípios, dos quais destacaremos os três seguintes, seguidos de algumas reflexões. 
I - igualdade de condições para o acesso e permanência na escola;

(...)

VI - gratuidade do ensino público em estabelecimentos oficiais;

(...)

IX - garantia de padrão de qualidade. (BRASIL, Lei nº 9394. Lei de Diretrizes e Bases da Educação Nacional. Planalto, 1996).

Como garantir o acesso à educação em comunidades que não tem acesso à internet ou a aparelhos eletrônicos? Como garantir a gratuidade do ensino, enquanto várias escolas pedem para que os alunos imprimam as atividades, acessem vídeo-aulas ou plataformas de ensino? Como garantir um padrão de qualidade sendo que a maioria dos professores só conhece o método tradicional de ensino e por muitos anos as aulas presenciais foram a única forma conhecida, trabalhada pelos professores?

Mesmo que a EAD tenha se desenvolvido no Brasil a partir do século XIX, o sistema educativo brasileiro básico, até agora, é tradicionalmente realizado por meio presencial. A utilização da tecnologia em sala de aula sempre foi muito tímida, principalmente nos primeiros anos escolares. (ROMANOWSKI et al. p.79, 2020)

Embora existam no Brasil diferentes plataformas de ensino à distância, elas se restringem a cursos de graduação e pós-graduação com plataformas próprias, preparadas já para existirem nesse formato. Como trazer esses modelos para a educação básica sem perder a qualidade, tentando minimizar as diferenças sociais e as dificuldades de aprendizagem fazendo com que a distância e o isolamento social afetem de maneira menor possível a qualidade de ensino? E qual tem sido o papel do gestor escolar nessa coordenação de trabalhos remotos? Tendo estas indagações como alicerces, optamos em desenvolver uma pesquisa de entrevistas a docentes e gestores das escolas públicas e particulares, na região de Itajubá, localizada no Sul do Estado de Minas Gerais, gerando assim alguns gráficos que iremos analisar.

\subsection{Gráficos da pesquisa quantitativa: análise dos primeiros impactos do Covid-19 na educação}

Gráfico 1 - Local de trabalho

\section{LOCAL DE TRABALHO}

घede Estadual $\quad$ Rede Municipal $\quad$ Rede Particular $\quad$ Municipal e Estadual

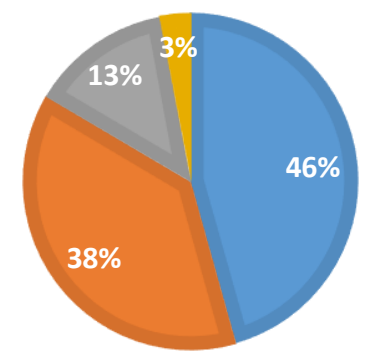

Fonte: Questionário (https:// forms.gle/6fTyoxjrSQx6Y7JN8 acesso em: 21/12/2020). 
Gráfico I: Em nosso primeiro gráfico indagamos o local de trabalho, dos participantes que foram um total de 103 pessoas, passando por gestores, docentes, professores de apoio, no qual tínhamos quatro opções referentes ao vínculo empregatício (Rede Estadual, Rede Municipal, Rede Particular, Rede Municipal e Estadual). Em que 46\% das pessoas trabalham na rede estadual, já $38 \%$ prestam serviços para a rede municipal, $13 \%$ de nossos entrevistados trabalham na rede privada de ensino, e por último, totalizando $3 \%$ dos entrevistados, que trabalham tanto na rede municipal como também na rede estadual de ensino.

Gráfico 2 - Função

\section{FUNÇÃO}

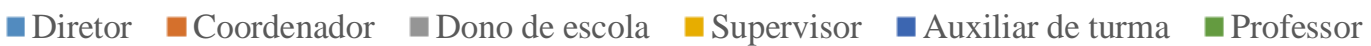

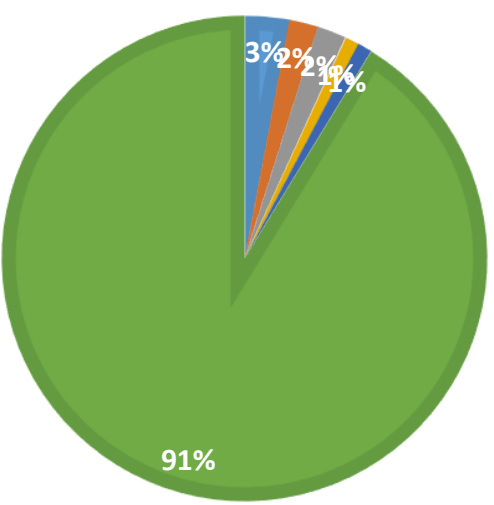

Fonte: Questionário (https://forms.gle/6fTyoxjrSQx6Y7JN8 acesso 21/12/2020.

Na segunda questão de nosso questionário foi perguntado qual a função que a pessoa desenvolve dentro da instituição de ensino. Entre a gestão escolar tivemos 3\% de respostas de diretores, $2 \%$ são coordenadores, $1 \%$ supervisores, e $2 \%$ são donos de escola, já no âmbito da docência tivemos $91 \%$ de professores e $1 \%$ de auxiliares de turma. 
Gráfico 3 - Medidas tomadas pela instituição de trabalho

$\begin{array}{ll} & \text { MEDIDAS TOMADAS } \\ \square \text { Vídeo conferência } & \square \text { Plataforma virtual de ensino } \square \text { Atividades impressas } \\ \square \text { Aulas gravadas } & \text { atividades on-line } \quad \text { Mesclou vídeo e impressa }\end{array}$

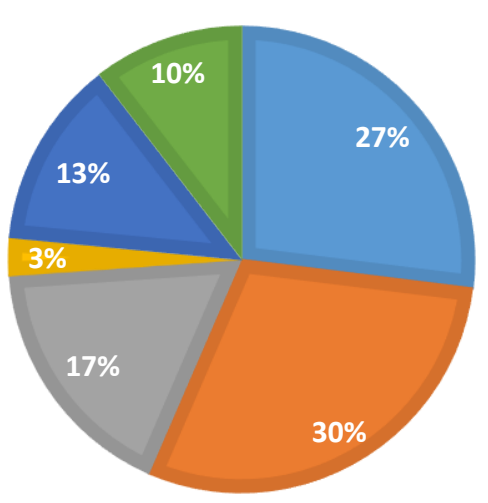

Fonte: Questionário (https://forms.gle/6fTyoxjrSQx6Y7JN8 acesso: 21/12/2020).

Já na terceira indagação foram exploradas as medidas tomadas nos lugares de ensino em que os participantes trabalham. $27 \%$ relataram a utilização de vídeo conferência ${ }^{2}$ como alternativa, já outros 3\% destacaram a alternativa de aulas gravadas, 30\% relataram a utilização das plataformas virtuais de ensino, $17 \%$ falaram do emprego de atividade impressa e enviada aos alunos, os últimos $13 \%$ usaram as atividades on-line.

Gráfico 4 - Decisões democráticas

\section{DEMOCRÁTICA}

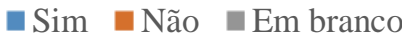

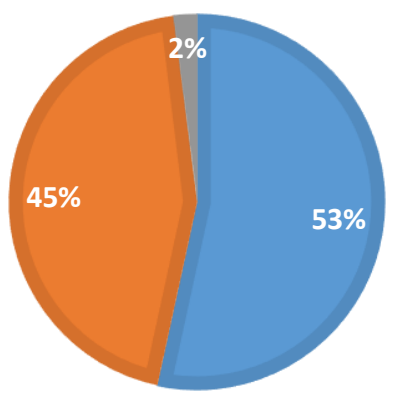

Fonte: Questionário (https:// forms.gle/6fTyoxjrSQx6Y7JN8 acesso 21/12/2020).

$\mathrm{Na}$ quarta pergunta questionamos se a tomada de decisões para o ensino remoto aconteceu de forma democrática cujas alternativas de resposta eram sim ou não. 53\% relataram que foi uma decisão democrática com a consulta de todos os agentes escolares e tivemos $45 \%$ de respostas

${ }^{2}$ Foi relatado pelos entrevistados diferentes plataformas como, por exemplo, google meet e zoom. 
dizendo que não houve um consenso democrático e que a opção no uso das mídias foi definida pelos superiores, já 2\% dos entrevistados optaram em não responder essa questão.

Gráfico 5 - Tempo de retomada das atividades remotas

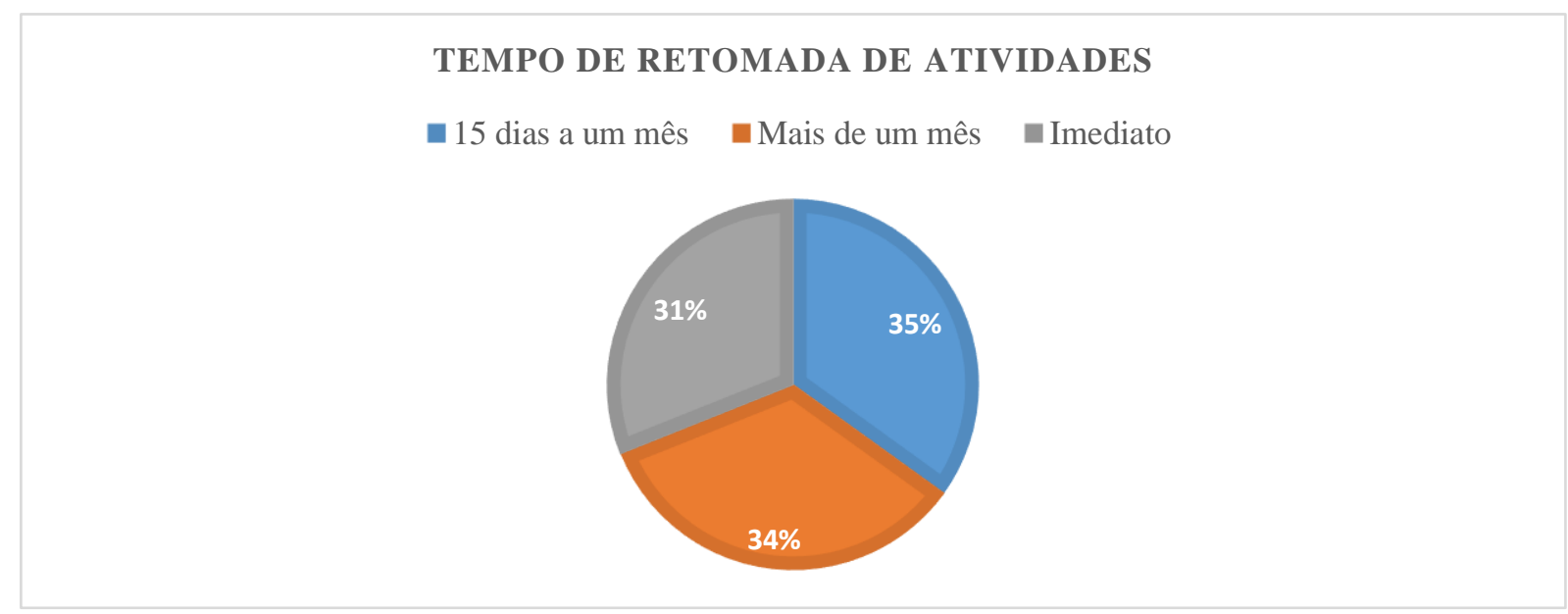

Fonte: Questionário (https:// forms.gle/6fTyoxjrSQx6Y7JN8 acesso 21/12/2020).

Tendo em vista a quinta pergunta de nosso questionário foi indagado: "Em quanto tempo a escola se organizou para início das aulas remotas?" 35\% dos entrevistados responderam que foi de quinze dias a um mês para a retomada das atividades. Já 34\% afirmaram que demorou mais de um mês para o retorno, já 31\% retrataram que a volta foi imediata logo após o início da pandemia no Brasil.

Gráfico 6 - Eficácia do ensino remoto

\section{EFICÁCIA}
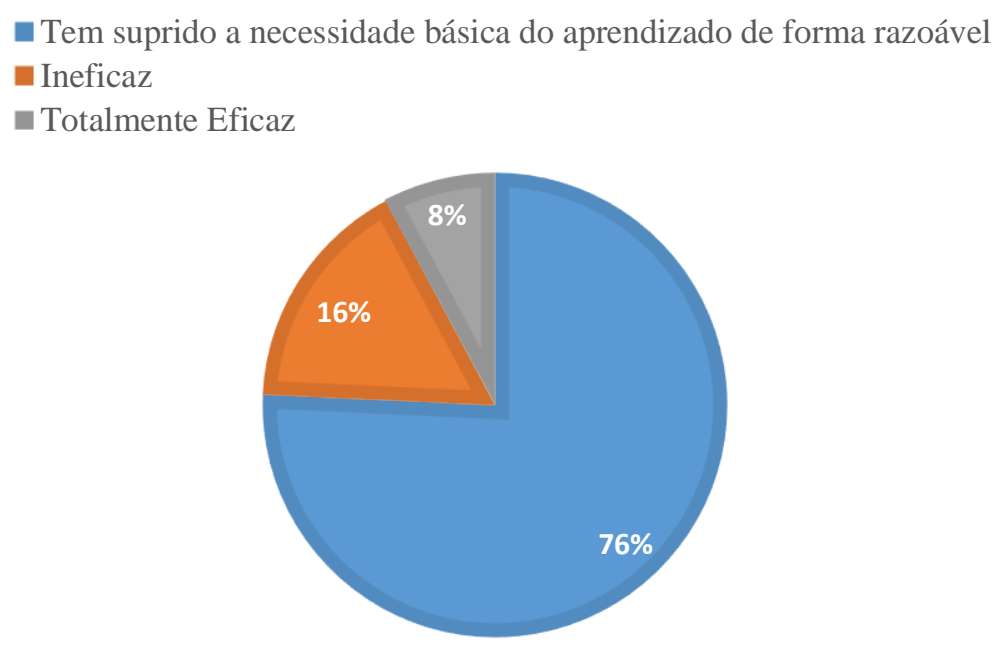

Fonte: Questionário (https:// forms.gle/6fTyoxjrSQx6Y7JN8 acesso 21/12/2020). 
Na sexta indagação "Como você considera a medida tomada na sua escola?" buscamos compreender a eficácia da retomada às atividades escolares no ano de 2020 de forma remota, em que $76 \%$ dos entrevistados entendem que a retomada das atividades não presenciais tem sido razoavelmente eficaz suprindo a necessidade básica da aprendizagem. Já 16\% dos profissionais que responderam ao questionário consideram a retomada das atividades ineficaz, mesmo com todos os esforços da comunidade escolar. $8 \%$ dos participantes afirmaram que a retomada através do ensino remoto é totalmente eficaz.

Gráfico 7 - Possibilidade do ensino remoto substituir o presencial

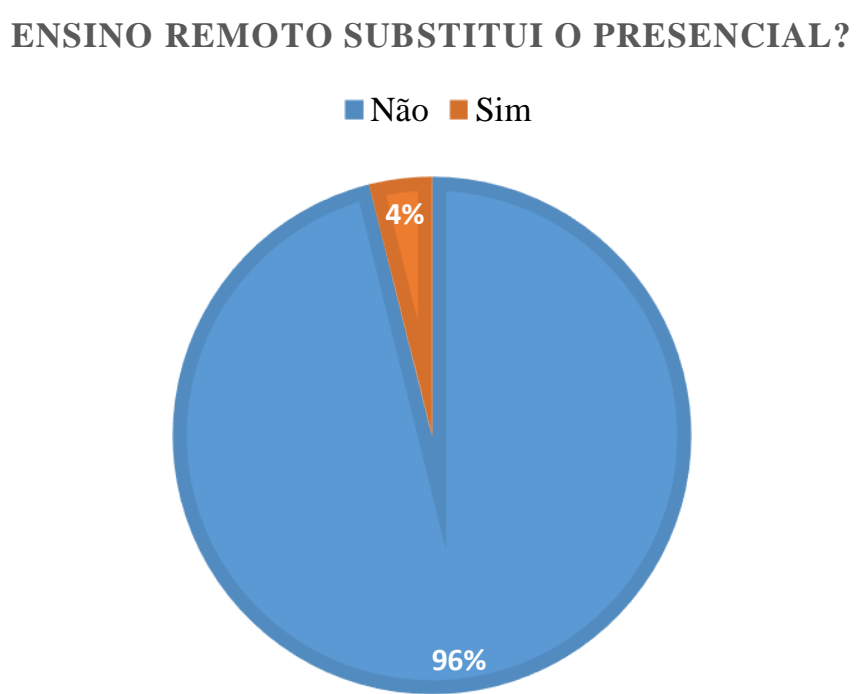

Fonte: Questionário (https://forms.gle/6fTyoxjrSQx6Y7JN8 acesso 21/12/2020).

$\mathrm{Na}$ sétima pergunta sobre a retomada das aulas no período de pandemia foi questionado "Você acredita que o ensino remoto substitui o presencial no contexto escolar que você trabalha?" E 96\% dos participantes disseram que o ensino remoto não substitui o ensino presencial, no entanto os outros $4 \%$ dos entrevistados afirmam que o ensino remoto pode substituir o ensino presencial. 
Gráfico 8 - Perdas financeiras

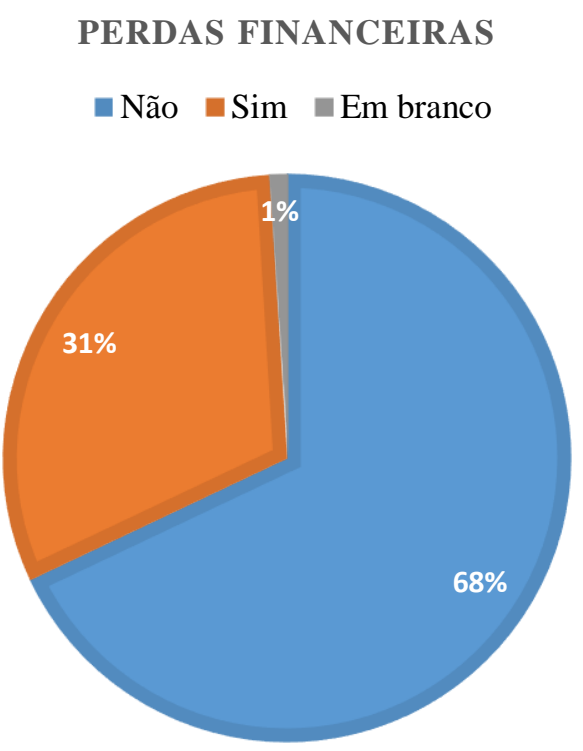

Fonte: Questionário (https://forms.gle/6fTyoxjrSQx6Y7JN8 acesso 21/12/2020).

$\mathrm{Na}$ oitava questão perguntamos a respeito das perdas financeiras durante a pandemia, no qual a indagação foi "A instituição que você trabalha presenciou perdas financeiras como redução de salários ou demissões?" $68 \%$ dos participantes afirmaram que não houve perda financeira durante o ano de 2020, já 31\% dos entrevistados relatam que houve sim uma perda nas finanças e 1\% optou em não opinar a respeito. É importante salientar nessa questão que apenas 13\% dos entrevistados estão ligados à rede particular de ensino e observar que na rede pública de ensino não há registros de redução de carga horária, tampouco de salários. 
Gráfico 9 - Evasão Escolar

\section{EVASÃO}

$\begin{array}{ll}\text { Menos de } 30 \% & \text { - } 30 \% \text { a } 50 \% \\ - \text { Mais que } 50 \% & \text { Não há registros }\end{array}$

- Ainda não é possível mensurar esses dados

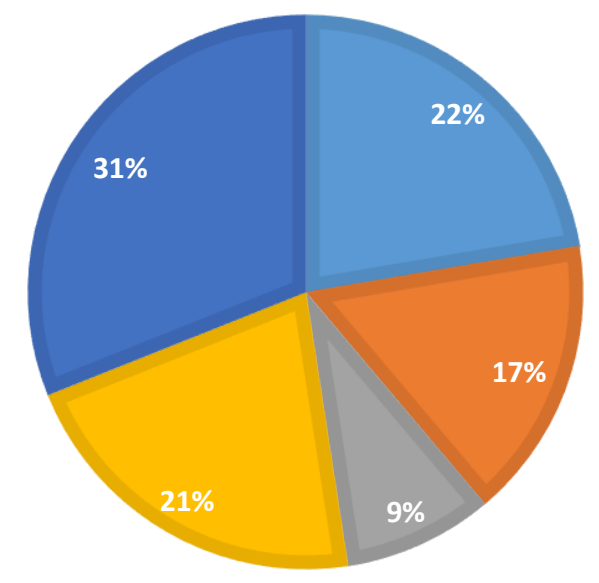

Fonte: Questionário (https://forms.gle/6fTyoxjrSQx6Y7JN8 acesso 21/12/2020).

Também foi perguntado sobre a porcentagem de alunos evadidos com a pandemia, no qual $31 \%$ declararam que ainda não é possível fazer este levantamento, já $22 \%$ afirmam que a perda foi menor do que 30\%, 21\% relatam que não há registros destes dados. Já 17\% colocam que a desistência está entre 30\% a 50\% dos alunos, e por último $9 \%$ dos entrevistados relatam que a desistência chegou a mais de $50 \%$ dos alunos matriculados. Também é importante ressaltar que o maior número de evasões se encontra na rede particular de ensino.

A última questão, cuja resposta não possuía opções, deixando aberto para uma reflexão, referia-se sobre as maiores dificuldades encontradas no trabalho e foi possível observar que grande parte dos entrevistados sentiram dificuldades com a adaptação com as novas tecnologias, seja na questão financeira, como compra de equipamentos e aquisição de internet de qualidade, tanto por parte dos professores quanto dos alunos. Foi citada também a falta de apoio da família para com as atividades e muitas vezes só obtiveram devolutiva dos trabalhos enviados após muita insistência, o que acabou se tornando um trabalho desgastante e excessivo, tomando mais tempo do que geralmente o profissional educacional gasta em suas atividades rotineiras além do trabalho burocrático com preenchimento de planilhas e relatórios de atividades. Foi levantado também que a coordenação escolar se encontrava despreparada para assessorar o trabalho do professor. Muitos também reclamaram da falta de interesse de participação dos alunos e da dificuldade em conciliar as atividades domésticas e familiares com o trabalho que passaram a ser no mesmo horário e ambiente o que em alguns casos gerou problemas de cunho emocional, principalmente para aqueles que 
perderam amigos ou familiares para a doença. E, por fim, a falta de acesso, afeto e contato pessoal também foram citadas como grande dificuldade elucidada.

Uma alternativa encontrada pela Secretaria do Estado de Educação de Minas Gerais foi a criação de um Plano de Estudo Tutorado (PET), no qual os alunos que não tem acesso aos meios virtuais, poderiam obter o material de forma impressa nas escolas. Porém foi observado um grande descaso por parte de alguns dos alunos, seja por não fazer as atividades, seja por perder o material e alguns casos do aluno e família nem buscar o material.

\section{Conclusão}

De uma forma geral, ao término da presente pesquisa, concluímos que o país apresenta uma série de dificuldades no âmbito do ensino remoto. Entre as dificuldades mais relevantes, destacamos o alto custo dos equipamentos multimídias, a rede de internet que não alcança todos os cidadãos e o despreparo dos profissionais de educação que não estão aptos a utilizar tais tecnologias. Bem como a falta de colaboração familiar para a realização e participação dos discentes nas aulas e devolutivas de materiais não tecnológicos.

Como o Brasil estava no processo de testes da vacina, no período que compreendeu o recorte desta pesquisa, o Coronavírus ainda causa grande número de mortos no país e as escolas não têm previsão de retomada das atividades presenciais consideramos que a nossa pesquisa pode ser continuada futuramente após o término da pandemia para podermos analisar as consequências desse contexto histórico juntamente com os reais impactos educacionais, uma vez que o presente trabalho levantou as dificuldades encontradas pela comunidade escolar em um primeiro momento de adaptação, todavia sendo ainda impossível mensurar os danos a longo prazo para toda geração estudantil em tempos de Covid-19.

\section{Referências}

CONGRESSO NACIONAL. Medida Provisória nº 934, de 2020 (Normas excepcionais sobre a duração do ano letivo). Brasília, DF. Disponível em: https://www.congressonacional.leg.br/materias/medidas-provisorias/-/mpv/141349 Acesso em: 08 dez. 2020

DECLARAÇÃO UNIVERSAL DOS DIREITOS HUMANOS. Assembleia Geral das Nações Unidas em Paris. 10 dez. 1948. Disponível em: https://www.unidosparaosdireitoshumanos.com.pt/course/lesson/articles-26-30/read-article-26.html. Acesso em: 07 dez. 2020.

DEUTSCHE WELLE (DW). Virus verbal: as frases de Bolsonaro sobre a pandemia. Berlim, Alemanha. Disponível em: https://www.dw.com/pt-br Acesso em: 09 dez. 2020. 
FIOCRUZ. As redes municipais de educação diante da pandemia. Rio de Janeiro, RJ. Disponível em: https://portal.fiocruz.br/noticia/redes-municipais-de-educacao-diante-da-pandemia Acesso em: 08 dez. 2020.

FUNDO NACIONAL DE DESENVOLVIMENTO DA EDUCAÇÃO. Alimentação escolar. Brasília, DF. Disponível em: https://www.fnde.gov.br/index.php/programas/pnae/pnae-perguntasfrequentes Acesso em: 07 dez. 2020.

PINHEIRO, Paulo Sérgio; MESQUITA NETO, Paulo de. Programa Nacional de Direitos Humanos: avaliação do primeiro ano e perspectivas. São Paulo, Disponível em: https://www.revistas.usp.br/eav/article/view/8999/10551. Acesso em: 07 dez. 2020.

ROMANOWSKI, Joana Paulin et al (org.). Educação e Tecnologias: desafios dos cenários de aprendizagem. Curitiba: Bagai, 2020.

SANARMED. Linha do tempo do Coronavirus no Brasil. São Paulo, SP. Disponível em: https://www.sanarmed.com/linha-do-tempo-do-coronavirus-no-brasil Acesso em: 07 dez. 2020.

SIMON, Pedro. Declaração universal dos direitos humanos: ideal de justiça, caminho e par. Brasília: Senado Federal, Secretaria Especial de Editoração e Publicações, 2008. Disponível em: https://www2.senado.leg.br/bdsf/handle/id/505869. Acesso em: 07 dez. 2020. 